\title{
Driver Behaviour with Adaptive Cruise Control
}

\author{
Neville A. Stanton* and Mark S. Young \\ School of Engineering and Design \\ Brunel University \\ Uxbridge \\ Middlesex \\ UB8 3PH \\ UK
}

\begin{abstract}
This paper reports on the evaluation of adaptive cruise control (ACC) from a psychological perspective. It was anticipated that ACC would have an effect upon the psychology of driving: i.e., make the driver feel like they have less control, reduce the level of trust in the vehicle, make drivers less situationally aware, but workload might be reduced and driving might be less stressful. Drivers were asked to drive in a driving simulator under manual and adaptive cruise control conditions. Analysis of variance techniques were used to determine the effects of workload (i.e. amount of traffic) and feedback (i.e. degree of information from the ACC system) on the psychological variables measured (i.e. locus of control, trust, workload, stress, mental models and situation awareness). The results showed that: locus of control and trust were unaffected by ACC, whereas situation awareness, workload and stress were reduced by ACC. Ways of improving situation awareness could include cues to help the driver predict vehicle trajectory and identify conflicts.
\end{abstract}

KEYWORDS: Automation, Driving, Workload, Stress, Trust, Situation Awareness

*author for correspondence, contact Neville.Stanton@brunel.ac.uk 


\section{AIMS OF PAPER}

Further to our call for more studies on vehicle automation to be published in the open literature (Stanton \& Young 1998), researchers are beginning to make their investigations public (e.g., Hoedemaeker 1999, Hoedemaeker \& Brookhuis 1998, Marsden et al 2001, Sonmezisik et al 1998). There is, however, a trend to concentrate on the failure of such systems (e.g., de Waard et al 1999, Desmond et al 1998) rather than how they will operate in normal use. Whilst it is prudent to consider the safety critical aspects of any new technology, it might also be considered limiting to focus on its failure. Ergonomics is in danger of being ignored by engineers if it fails to communicate how best to implement new technology. Furthermore, the current movement is towards proactive design solutions, rather than reacting to accidents or failures (e.g., Wickens et al 1998). In that vein, Young \& Stanton (1997) argued that research effort might be better spent investigating how we should design automation systems to optimize performance, given that their implementation is inevitable. Therefore, the aim of this paper is to indicate which aspects of driver psychology are likely to be important and investigate their application to adaptive cruise control. There appears to be a growing consensus amongst the Ergonomics community about which psychological factors are likely to be the best candidates for investigation. In a previous paper (Stanton \& Young 2000), we suggested that researchers should consider: locus of control, trust, situation awareness, mental representations, workload, and stress. These factors are at issue in other environments where automation is considered, such as aviation (Billings 1993) and process control (Hancock 1997). They have been further confirmed in the automotive context by leading researchers, such as the keynote address by Parasuraman (2000) at the International Conference on Engineering Psychology and Cognitive Ergonomics in Edinburgh. This gives us some degree of confidence that the six factors are likely to be the most important variables in driving automation. To put the research into context, we will first explain how adaptive cruise control works, before considering the psychological issues in greater detail.

\subsection{ADAPTIVE CRUISE CONTROL}

Adaptive cruise control (ACC) is based on a range sensor and a distance control system which are linked to a conventional cruise control system. Contemporary systems also have some limited braking authority, up to $0.3 \mathrm{~g}$, which together with the throttle control the speed of the ACC-equipped vehicle and the time-based separation from the vehicle in front. In the Jaguar XK series, a microwave radar is used as the range sensor. This was found to be superior to the laserbased equivalent, as it is less likely to be affected by environmental conditions (Richardson et al. 1997). The radar has been designed to detect only vehicles travelling in the same lane as the ACC vehicle. The control system comprises a speed controller and a headway controller. The control system switches between speed and headway control in response to data from the range sensor. In order to achieve the speed and headway, it has authority over the throttle and brakes. Unlike conventional cruise control (CCC) which has five operational modes (off, on, cruising, 
driver override, and standby), ACC has a sixth "following" mode. The differences in system state between CCC and ACC are shown in figures 1 and 2 respectively.

\section{INSERT FIGURE 1 ABOUT HERE}

As figure 1 shows, once switched on, CCC can be put into cruising mode by setting the cruising speed. The system can move from cruising mode to four other modes, if the driver accelerates, brakes, cancels the set speed or switches CCC off. If the driver accelerates, the system automatically returns to cruise mode after the period of intervention. If the driver brakes, then CCC is put into standby mode and the vehicle is under manual control. From standby mode the driver can either resume cruise mode or reset the cruising speed. The driver can choose to switch the system off from any of the other modes. The control modes for adaptive cruise control are shown in figure 2.

\section{INSERT FIGURE 2 ABOUT HERE}

As with CCC, the ACC system can switch between control modes: from off to on, from on to cruising, from cruising to intervene, from intervene to standby, from standby to off. The additional following mode means that the driver does not have to brake when the car closes on another vehicle. On these occasions, the car moves from cruising mode into following mode. If the vehicle in front moves out of the way of the ACC-equipped car, then the system will revert back to cruising mode. The driver is at liberty to override both cruising and following modes, as shown in figure 2.

Stanton \& Young (1998) argued that the addition of the extra mode had a dramatic effect on the nature of the cognitive tasks of the driver. The apparently simple removal of the physical braking task would, on the face of it, reduce driver workload. There has been some dispute over whether or not driving with ACC is accompanied by workload reductions. Nilsson (1995) and Young \& Stanton (1997) suggest that workload is about the same as for manual driving, whereas the study by Stanton et al (1997) suggests that there are workload reductions. The driver's tasks with CCC and ACC are compared in figure 3.

The tasks for CCC and ACC as shown in figure 3 suggest that removing the physical task of braking, adds a cognitive overhead of checking that the vehicle is behaving appropriately in response to changes in the road environment. Instead of braking when a vehicle is detected when using CCC, the driver of an ACC vehicle has to check that the ACC system has detected the vehicle, and that it is braking and that an appropriate headway is maintained for the duration that the following mode is operational. Thus it would seem that whilst physical workload is reduced, 
mental workload is increased. These two types of workload might cancel each other out, showing no net increase, nor decrease, in overall workload. Workload and other psychological issues will be presented next.

\section{INSERT FIGURE 3 ABOUT HERE}

\subsection{DRIVER BEHAVIOUR}

Now that the operational characteristics of ACC have been presented, the potential impact on the driver can be considered. Studies that report the effects of automation on driver behaviour typically report on only one or two psychological variables such as stress (Desmond et al., 1998) or workload (de Waard et al., 1999) in addition to the performance measures of driving (such as speed, leading headway and position in lane). In this paper we are aiming to consider six factors that we suspect are likely to be affected by automation of longitudinal control. In addition to workload and stress, which have previously been shown to be affected, we also plan to consider locus of control, trust, situation awareness, and mental representations. Each short overview will contain a summary of the main issues and an experimental hypothesis $(\mathrm{H})$. A detailed review of the factors may be found in Stanton \& Young (2000).

One of the biggest unknowns in ACC operation is the reaction of the driver to the apparent loss of some of their driving autonomy. The idea that locus of control might have an effect upon performance is not new. Locus of control is determined by the extent to which drivers attribute their own activities as responsible for the behaviour of the vehicle (an internal locus of control) or whether the behaviour of the vehicle is due to the automated system (an external locus of control). An external locus of control might lead an individual to assume a passive role with the automated system, whereas an internal locus of control may lead individuals to assume an active role. Research in other domains suggests that people with an internal locus of control generally perform better than individuals with an external locus of control (Rotter 1966, Parkes 1984). We wonder if the degree of internality/externality reported might, to some extent at least, be affected by the environment. Do drivers in the automated condition report greater externality than when they are in the manual condition (Hypothesis 1: H1)?

Muir (1994) proposed a model of trust between human and automated systems that could be applied to vehicle automation. This identifies three main factors of trust as predictability, dependability and faith. The relationship between predictability, dependability and faith in humans is supposed to be temporal, i.e. predictability is the basis of dependability, which in turn leads to faith. If experience with a machine provides predictable outcomes, then an individual may start to depend upon that system. The increase in dependency may be observed by a decrease in sampling behaviour as the outcome proves to be predictable. Increased dependency 
may lead the individual to impart a degree of faith in the machine that implies qualities beyond those directly observed. We anticipate that drivers might have greater trust in the ACC system with higher levels of feedback (H2), despite the fact that Muir \& Moray (1996) also show that their participants would rather do the task manually than leave it to an automatic system.

Research on situation awareness in aviation and process control shows that the separation of perceived machine state from actual machine state leads to operational problems (Woods 1988). This would imply that situation awareness of the ACC system and the road environment is crucial for optimum performance. Endsley's (1995) model of situation awareness proposes three levels of understanding: perception of the elements (e.g., reading the set speed), comprehending the situation (e.g., knowing that the vehicle is following a leading vehicle), and projecting future status (e.g., anticipating the trajectory of the vehicles and identifying any potential conflicts). From the research literature on automation and situation awareness (Woods 1988), it is anticipated that drivers with ACC will have less awareness of the situation when compared to manual driving (H3).

The concept of mental models is linked to situation awareness, as an understanding of the current situation and projecting the future relies upon some model of the world and behaviour of system elements. Internal mental representations about the behaviour of devices are built up from exposure (Johnson-Laird 1989). The accuracy of the models is determined by the effectiveness of the system interfaces (Norman 1988) and variety of situations encountered. There are often approximations and incompleteness in these models, but they serve as working heuristics (Payne 1991). These models can sometimes be wildly inaccurate (Caramazza et al. 1981). We anticipate that the accuracy of the mental model of the ACC system may be improved with higher levels of feedback (H4), as this informs the development of the model and helps the driver interpret what is going on.

There is still some controversy about whether ACC reduces workload or not. Some studies suggest that activating ACC is accompanied by reduction in driver workload (e.g., Stanton et al. 1997), whereas others suggest that it is not (e.g., Young \& Stanton 1997). In other domains, it has been claimed that automation actually increases workload, rather than reduces it (Reinartz \& Gruppe 1993). There is no doubt that driving with ACC is quite different to driving with CCC, as figure 3 illustrates. The two tasks are qualitatively different. Whilst ACC subtracts the physical task of depressing the brake pedal, it adds the task of monitoring the ACC system to ensure that it is operating effectively. This task swap might support the notion that overall workload is likely to remain unchanged (H5). As this is a null hypothesis, it is quite likely to be supported 
Driver stress has become a subject of much research in recent years. This research suggests that it is fatigue from the lack of stimuli that drivers find most stressful, i.e., task underload rather than task overload (Matthews \& Desmond 1995, Matthews et al 1996). Matthews et al. (1996) report that when the driving task is relatively difficult fatigued drivers perform significantly better than when the driving task is easy. Matthews \& Desmond (1995) suggest that in-car systems should be designed to create more attentional demand, not less. This seems to be counter to the research and development effort in vehicle automation, which is aimed at reducing driver workload. From this we might hypothesize that driving with ACC will be more stressful (H6). However, driving in congested traffic increases stress, which has been linked to road traffic offences (Simon \& Corbett 1996). From this we might hypothesize that under high traffic conditions, ACC will actually reduce stress (H7).

\section{METHOD}

The experimental method used in the main study was as follows.

\subsection{Participants}

The study employed 110 participants. They were recruited from the University of Southampton campus and via the local media. Ethical permission to conduct the research was sought and granted from the Department of Psychology at the University of Southampton. Participants were selected to reflect the age and gender of the driving population at large in the UK. Forty two of the participants were female. The mean age was 33.6 years (minimum 18 years, maximum 73 years, standard deviation 12.7 years). The mean driving distance per annum of participants was 16.9 thousand kilometers (10.5 thousand miles) with a standard deviation of 10.6 thousand kilometers (6.6 thousand miles). Participants were randomly assigned to experimental conditions to match for age and gender.

\subsection{Design}

There were three independent variables (automation (with two within-subjects levels of manual driving and ACC driving), workload (with three between-subjects levels of high, medium and low) and feedback (with three between-subjects levels of high, medium and low)), two dependent variables associated with driving behaviour (speed and lateral position on road) and six dependent variables associated with the psychology of the driver (locus of control, trust, workload, stress, mental models and situation awareness). The assignment of numbers of participants to the experimental conditions is illustrated in table one.

\section{INSERT TABLE 1 ABOUT HERE}


The three levels of workload were determined by manipulating the throughput of vehicles per hour (VPH) as follows: $800 \mathrm{VPH}$ (Low), $1600 \mathrm{VPH}$ (Medium) and $2400 \mathrm{VPH}$ (High). The three levels of feedback were manipulated by the degree of information provided by the ACC system as follows: auditory feedback only (Low); auditory feedback, plus standard messages on ACC display embedded in the instrument panel (Medium); and auditory feedback, plus standard messages on ACC display embedded in the instrument panel, together with a head-up display of the same information. There was no manipulation of feedback in the manual condition.

\subsection{Equipment}

The equipment comprised a fixed-base driving simulator based on the Jaguar XK8 and a series of tools to measure the dependent variables. It is a semi-immersive environment, with the emphasis on psychological and operational fidelity, placing it in the mid-range of driving simulators.

Transducers connected to the steering, brake and accelerator send digital signals to an Acorn Archimedes RISC PC. Software inside the computer interpret the signals to position the driver's trajectory along a motorway-type road. The driver is presented with a three-lane motorway on a projection screen viewed through the windscreen of the XK8 via an Epson colour LCD projection monitor. The simulation is fully interactive: the driver has full vehicle control and may interact with other vehicles on the road. The data logged include: speed, position on the road, distance from other vehicles, steering wheel and pedal positions, overtakes, and collisions (taken every 0.5 seconds automatically by the simulator software). The ACC interface comprised a Liquid Crystal Display in the instrument cluster and a set of buttons inset into the steering wheel. A separate PC was used to drive this interface (an Elenex PC-466/1 and monitor). A Panasonic VCR NV-180 video recorder was used to record each participant's drive, so that pertinent parts of the drivers' interaction with the ACC could be assessed in a playback session.

The dependent measures were collected using the following tools:

(i) A multidimensional trust scale based upon Muir (1994)

(ii) The Locus of Control inventory (LOCI) from Rotter (1966)

(iii) Driving Internality-Externality (MDIE) scales from Montag \& Comrey (1987)

(iv) A subjective, multidimensional, workload scale: the NASA-TLX (Hart \& Staveland 1988)

(v) The Dundee Stress State Questionnaire (DSSQ: Matthews et al unpublished)

(vi) Situation Awareness Rating Technique (SART) (Taylor et al 1995)

(vi) Two questionnaires about ACC operation: a ten-item multiple-choice questionnaire and a series of 'what happens next' scenarios, to which a free-form response is required. These measures were developed by the researchers specifically for this project. 
(vii) A post-task verbal protocol was used to assess how well participants were able to explain their actions with ACC in the driving context. A video cassette player (Panasonic VCR NV-180) and monitor (LG $33.6 \mathrm{~cm}$ (14 inch) colour TV) were used.

\subsection{Procedure}

The experimental procedure was as follows:

(i) On agreeing to participate, a time for the study was arranged and participants met the experimenter at his office.

(ii) On arrival, participants were escorted to the driving simulator laboratory.

(iii) Participants were briefed immediately prior to the study as follows: "This study is investigating a new vehicle technology called Adaptive Cruise Control. In a moment, I will ask you to drive a practice run in the simulator, followed by two test runs. There are some questionnaires to be completed before and after these runs. At the end of the study, you will receive $£ 10$ for your participation. You are free to withdraw from the study at any time. Unless you have any objections about the study, would you please sign this consent form."

(iv) The participant then signed the consent form.

(v) Then the participant completed the three pre-trial questionnaires on a computer, in order to establish pre-driver scores for the DSSQ, Rotters I-E scales and the MDIE.

(vi) The participant was then asked to read the ACC manual to familiarize themselves with its operation and behaviour.

(vii) When the participant was satisfied that they understood the operation of the ACC system, they were allowed to have a practice drive of the simulator for five minutes under both ACC and manual control.

(viii) Participants who were undertaking the manual driving condition first had the following instructions: "You are on your way to work, which involves a 20 minute motorway drive. You are requested to keep your speed as close to $113 \mathrm{~km}$ (70 mph) as possible. Other than that you should drive in your normal manner."

(ix) Participants who were undertaking the ACC driving condition first had the following instructions: "You are on your way to work, which involves a 20 minute motorway drive. You are requested to keep your speed as close to $113 \mathrm{~km}$ (70 mph) as possible. You should engage the ACC system as soon as possible with a set speed of $113 \mathrm{~km}$ (70 mph) and leave it engaged for the remainder of the journey. Other than that you should drive in your normal manner."

(x) After completing each drive, participants completed the NASA-TLX, SART, and DSSQ questionnaires on the computer. If they had completed the ACC drive, they also 
completed the mental model questionnaires and the trust questionnaire. Neither of these questionnaires were relevant to the manual condition.

(xi) After both drives, participants were debriefed on the nature of the study and received £10 payment.

\subsection{Analysis}

Analysis of variance (ANOVA) technique was used to see if manipulation of the three independent variables (i.e., automation, workload and feedback) had any effect upon the dependent variables (i.e., driving variables: speed and lateral position on road; and psychological variables: locus of control, trust, workload, stress, mental models, and situation awareness). Post-hoc contrasts and independent t-tests were computed for statistically significant differences.

\section{RESULTS}

ANOVAs were conducted on all of the driving and psychological variables. The results are reported below.

\subsection{Driving variables}

A statistically significant main effect of traffic level was found for driving speed $(\underline{F}(2,101)=20.0$, $\mathrm{p}<0.001$ ) as shown in figure 4. As traffic level increased, so the participants' speed decreased ( $\mathrm{p}<0.001$ from low to medium; $\mathrm{p}<0.01$ from medium to high).

\section{INSERT FIGURE 4 ABOUT HERE}

A statistically significant main effect of traffic level was found for lateral road position $(\underline{F}(2,101)=19.0, \underline{p}<0.001)$ as shown in figure 5 . On the $y$-axis in figure 2 , zero refers to the offside edge of lane one (the left lane as driven in the UK), with minus five as the left edge of the road, and plus five as the divider between lanes two and three. Hence, as traffic level increased from low to medium, so the lateral position of the participants moved to the right $(\mathrm{p}<0.001)$.

\section{INSERT FIGURE 5 ABOUT HERE}

\subsection{Locus of control}

Analysis of the responses recorded on Rotter's locus of control scale showed no statistical differences due to either feedback $(\underline{F}(2,101)=1.76, \underline{p}=n s)$ or traffic level $(\underline{F}(2,101)=1.01, \underline{p}=n s)$. In addition, the interaction between feedback and traffic was not significant for the LOCI scores $(\underline{F}(4,101)=0.284, \underline{p}=n s)$. 
Analysis of the MDIE scales revealed differences between participants on both the internality $(\underline{F}(2,101)=3.29, \underline{\mathrm{p}}<0.05)$ and externality $(\underline{\mathrm{F}}(2,101)=4.08, \underline{\mathrm{p}}<0.05)$ scales in the pre-trial measures. Post hoc t-tests show that participants in the medium-level traffic condition report higher levels of internality than those in the low-level $(\mathrm{p}<0.05)$ and high-level $(\mathrm{p}<0.05)$ conditions. The medium-level participants also report lower levels of externality than those in the low-level condition $(\mathrm{p}<0.05)$.

\subsection{Workload}

The measure of workload was analysed as both the cumulative score of overall workload and at the level of individual scales on the NASA-TLX (i.e., mental demand, physical demand, temporal demand, performance, effort and frustration). There were statistically significant differences in the level of workload between the experimental conditions. First, there was higher overall workload in the manual condition compared to the ACC condition $(\underline{F}(1,101)=15.0$, $\mathrm{p}<0.001)$. Second, there were differences in the levels of workload associated with the levels of traffic $(\underline{F}(2,101)=5.95, \underline{\mathrm{p}}<0.005)$. Repeated contrasts were used to explore these differences further. Specifically, overall workload in the medium-traffic level condition was higher than the low-traffic level condition ( $\mathrm{p}<0.005)$, whilst overall workload in the high-traffic level condition was no different to the low-traffic level condition, suggesting a ceiling effect in the medium- and high-traffic level conditions.

There were statistically significant differences in mental demand for automation $(\underline{F}(1,101)=14.3$, $\mathrm{p}<0.001$ ), where mental demand was higher in the manual condition compared to the ACC condition, and for the level of traffic $(\underline{F}(2,101)=6.61, \underline{p}<0.005)$. These effects were further explored with repeated contrasts. Mental demand in the medium-traffic condition was higher than the low-traffic condition $(\mathrm{p}<0.005)$, but there was no statistical difference between mental demand in the medium-traffic and the high-traffic conditions, again suggesting a ceiling effect. There was also a complex three-way interaction between automation, traffic demand and feedback level for mental demand $(\underline{F}(4,101)=2.73, \underline{p}<0.05)$. When traffic demand is low, the low and medium feedback conditions led to higher mental demand in the manual condition $(\mathrm{t}(11)=-$ 2.42, $\mathrm{p}<0.05$ for low feedback; $\underline{\mathrm{t}}(11)=-2.26$; $\mathrm{p}<0.05$ for medium feedback). Furthermore, when traffic demand is high, medium feedback also results in significantly higher mental demand in the manual condition ( $\mathrm{t}(11)=-3.84 ; \mathrm{p}<0.005)$.

For the remaining variables, the manual condition led to higher ratings on physical demand $(\underline{F}(1,101)=12.9, \underline{\mathrm{p}}<0.005)$, temporal demand $(\underline{F}(1,101)=6.65, \underline{\mathrm{p}}<0.05)$, and perceived effort $\left(\underline{F}(1,101)=16.1, \underline{p}^{<0.001)}\right.$. There were no statistically significant results for the performance variable of the TLX. 
Finally, statistically significant differences were found between the traffic levels on frustration $(\underline{F}(2,101)=3.90, \underline{p}<0.05)$, with repeated contrasts revealing higher levels of frustration in the medium-traffic condition when compared to the low-traffic condition $(\mathrm{p}<0.05)$. No statistical differences were found between the high and medium-traffic demand conditions. There was also a significant interaction between automation and feedback $(\underline{F}(2,101)=3.13, \underline{p}<0.05)$. Paired $t-$ tests confirmed that frustration was significantly higher when driving manually only in the medium feedback condition $(\mathrm{t}(37)=-2.44, \underline{\mathrm{p}}<0.05)$. Furthermore, when driving with ACC, there was a significant increase in frustration from the medium to high feedback levels $(\mathrm{p}<0.05$ using Scheffe comparisons on a one-way ANOVA). Figure 6 illustrates these results.

\section{INSERT FIGURE 6 ABOUT HERE}

\subsection{Situation awareness}

Situation awareness (SA) in the SART questionnaire is divided into overall SA and three main subscales: demand on attentional resources (which is further sub-divided into scales of: instability of situation, complexity of situation, variability of situation), supply of attentional resources (which is further sub-divided into scales of: arousal, concentration of attention, divided attention, spare mental capacity) and understanding of situation (which is further sub-divided into scales of: information quantity, information quality, familiarity with situation). This framework will be used to structure the analyzes.

Analysis of overall situation awareness found an interaction between the traffic levels and the level of feedback $(\underline{F}(4,101)=2.84, \underline{\mathrm{p}}<0.05)$ as shown in figure 4 . Follow-up one-way ANOVAs using Scheffe post hoc tests found significant differences between feedback conditions in the low traffic level $(\underline{\mathrm{F}}(2,71)=5.46, \underline{\mathrm{p}}<0.01)$, with low feedback leading to higher situation awareness than high feedback $(\mathrm{p}<0.01)$. Similarly, low feedback led to differences in situation awareness across traffic levels $(\underline{F}(2,71)=7.11, \underline{p}<0.005)$, with low traffic resulting in higher situation awareness than high traffic $\left(\mathrm{p}^{<0.005)}\right.$.

\section{INSERT FIGURE 4 ABOUT HERE}

Analysis of the main sub-scale of demand on attentional resources found a main effect for automation, with higher demand in the manual condition $(\underline{F}(1,101)=13.5, \underline{p}<0.001)$.

There was an automation main effect for the sub-scale of instability $(\underline{F}(1,101)=15.1, \underline{p}<0.001)$, with higher rated instability in the manual condition. A traffic main effect revealed differences between traffic levels and reported instability $(\underline{F}(2,101)=7.30, \underline{p}<0.005)$. Repeated contrasts revealed that the levels of instability were lower in the low traffic level when compared to the medium ( $\mathrm{p}^{<0.001)}$, but not between medium and high traffic levels. Some of these effects might 
be due the higher proportion of 'internals' in the medium-traffic level condition. There was also an interaction between traffic levels and automation for instability $(\underline{F}(2,101)=3.35, \underline{p}<0.05)$. A one-way ANOVA with Scheffe comparisons revealed that instability in the ACC condition varied across traffic levels $(\underline{F}(2,109)=10.8, \underline{p}<0.001)$, with the medium traffic level condition being rated higher on instability than the low traffic condition $(\mathrm{p}<0.001)$. The manual condition was rated higher on instability compared to the ACC condition in the low traffic level $(\underline{\mathrm{t}}(35)=3.94, \underline{\mathrm{p}}<0.001)$ and high traffic level $(\mathrm{t}(35)=-2.6, \underline{\mathrm{p}}<0.05)$ conditions. Across automation conditions, instability was higher for manual driving in the low $(\mathrm{t}(35)=-3.94, \mathrm{p}<0.001)$ and high $(\underline{t}(35)=-2.60, \underline{p}<0.05)$ traffic demand conditions.

A main effect for traffic level was found for the rating of complexity $(\underline{F}(2,101)=5.34, \underline{p}<0.01)$. Repeated contrasts revealed that complexity was rated significantly lower in the low traffic level condition compared to the medium demand condition, $(\mathrm{p}<0.005)$ but there was no difference between medium and high conditions.

There was a main effect of traffic level for variability of situation $(\underline{F}(2,101)=4.76, \underline{p}<0.05)$. Variability was rated higher in the medium traffic condition than both the low $(\mathrm{p}<0.005)$ and high $(\mathrm{p}<0.05)$ traffic conditions. There was also an interaction between traffic and feedback for variability $(\underline{F}(4,101)=2.97, \underline{\mathrm{p}}<0.05)$. One-way ANOVAs with Scheffe post-hoc tests found significant differences across feedback levels within the medium $(\underline{F}(2,75)=3.20, \underline{p}<0.05)$ and high $(\underline{\mathrm{F}}(2,71)=3.19, \underline{\mathrm{p}}<0.05)$ traffic conditions. In medium traffic, medium feedback resulted in higher variability than high feedback $(\mathrm{p}<0.05)$. Across traffic conditions, there were significant differences in variability within the medium feedback group $(\underline{F}(2,75)=13.2, \underline{p}<0.001)$. Medium traffic resulted in higher variability than both the low $(\mathrm{p}<0.001)$ and high $(\mathrm{p}<0.005)$ traffic conditions. These results are illustrated in figure 5 below.

\section{INSERT FIGURE 5 ABOUT HERE}

Manual driving led to higher ratings than ACC across the sub-scales of supply of attentional resources $(\underline{F}(1,101)=15.8, \underline{\mathrm{p}}<0.001)$, arousal $(\underline{\mathrm{F}}(1,101)=7.77, \underline{\mathrm{p}}<0.01)$, concentration $(\underline{F}(1,101)=12.7, \underline{\mathrm{p}}<0.005)$, and familiarity $(\underline{F}(1,101)=17.5, \underline{\mathrm{p}}<0.001)$.

An interaction effect was found between automation and feedback for spare capacity $(\underline{F}(2,101)=3.68, \underline{p}<0.05)$, where there was greater spare capacity in the ACC condition compared to the manual condition only under the medium traffic level $(\mathrm{t}(37)=2.56, \mathrm{p}<0.05)$. 
A main effect for traffic levels was found for information quantity $(\underline{F}(2,101)=4.40, \underline{p}<0.05)$. Information quantity was rated higher in the medium traffic level than the high traffic level $(\mathrm{p}<0.005)$, whilst there was no difference between low and medium traffic conditions.

An interaction effect between automation and feedback was found for information quality $(\underline{F}(2,101)=5.12, p<0.01)$. Information quality was rated higher in the ACC condition compared to the manual condition at medium traffic levels $(\underline{t}(37)=2.62, \underline{\mathrm{p}}<0.05)$.

\subsection{Trust}

Since the trust questionnaire was only administered after the ACC trial, a univariate ANOVA was performed on these data. No statistically significant results were found for levels of overall trust on either the feedback $(\underline{F}(2,101)=0.177, \underline{p}=n s)$ or traffic conditions $(\underline{F}(2,101)=0.612, \underline{p}=n s)$, nor was there a significant interaction between these $(\underline{F}(4,101)=1.63, \underline{p}=n s)$.

\subsection{Mental models}

No statistically significant results were found for any of the measures of mental representations between the experimental conditions. The statistics are summarized in table 2 below.

\section{INSERT TABLE 2 ABOUT HERE}

\subsection{Stress}

The DSSQ is subdivided into scales of: anger, concentration, control and confidence, hedonic tone, motivation, self-esteem, self-focused attention, task-irrelevant interference, task-related interference, and tense arousal. This list of scales will serve as a means of ordering the sequence of analyses. This scale is also unique in that there are three levels of the automation factor, as a pre-drive baseline measure was collected.

The analysis of the anger scales revealed a main effect of automation $(\underline{F}(2,202)=6.12, \underline{p}<0.005)$. Simple contrasts using the pre-drive scores as the reference category revealed that anger scores were higher in the manual condition than the pre-driving condition $(\mathrm{p}<0.05)$.

There was also a main effect of automation for the concentration scores $(\underline{F}(2,202)=3.75, \underline{p}<0.05)$. Concentration scores were higher in the ACC condition than the pre-driving condition $(\mathrm{p}<0.05)$. There was also a complicated three-way interaction effect between automation, feedback and traffic levels $(\underline{\mathrm{F}}(8,202)=2.20, \underline{\mathrm{p}}<0.05)$. This interaction is illustrated in figure 6 .

\section{INSERT FIGURE 6 ABOUT HERE}


As graph 6 shows, the reported concentration levels for medium feedback were more consistent across traffic levels than for low or high feedback in the ACC condition. High feedback appears to have required more concentration in the low traffic demand condition and low feedback appears to have required more concentration in the medium traffic demand condition.

Analysis of the control and confidence scale revealed a main effect for automation $(\underline{F}(2,202)=41.6, \underline{p}<0.001)$. Control and confidence was higher in the pre-driving condition than in the manual condition $(\mathrm{p}<0.001)$ and the ACC condition $(\mathrm{p}<0.001)$. There was also an interaction between automation and the traffic level $(\underline{F}(4,202)=3.82, \underline{p}<0.01)$, as shown in figure 7.

\section{INSERT FIGURE 7 ABOUT HERE}

There was also a traffic level main effect for control and confidence $(\underline{F}(2,101)=4.14, \underline{p}<0.05)$ as illustrated in figure 7. Repeated contrasts showed that control and confidence was higher in the medium traffic level condition than in the high traffic level condition $(\mathrm{p}<0.01)$, but there was no difference between the low and medium demand conditions.

Analysis of the hedonic tone scale revealed a main effect for automation $(\underline{F}(2,202)=34.3$, $\mathrm{p}<0.001)$. Hedonic tone was higher in the pre-driving condition than in the manual condition $(\mathrm{p}<0.001)$ and the ACC conditions $(\mathrm{p}<0.001)$.

There was also a traffic level main effect for hedonic tone $(\underline{F}(2,101)=3.20, \underline{p}<0.05)$. Hedonic tone was higher in the medium traffic level condition than in the high traffic level condition $(\underline{p}<0.05)$, with no difference between low and medium demand conditions.

An automation main effect was found for the motivation scale $(\underline{F}(2,202)=14.4, \underline{p}<0.001)$.

Motivation was higher in the pre-driving condition than in the ACC condition $(\mathrm{p}<0.001)$ and the manual condition $(\mathrm{p}<0.001)$.

An automation main effect was found for the self-esteem scale $(\underline{F}(2,202)=47.6, \underline{p}<0.001)$. Selfesteem was higher in the pre-driving condition than in the ACC condition $(\mathrm{p}<0.001)$ and the manual condition $(\mathrm{p}<0.001)$.

An automation main effect was found for the self-focused attention scale $(\underline{F}(2,202)=125.6$, $\mathrm{p}<0.001$ ). Self-focused attention was higher in the pre-driving condition than in the ACC condition ( $\mathrm{p}<0.001)$ and the manual condition $(\mathrm{p}<0.001)$. 
An automation main effect was found for the task-irrelevant interference scale $(\underline{F}(2,202)=46.2$ $\mathrm{p}<0.001)$. Task-irrelevant interference was higher in the pre-driving condition than in the ACC condition $(\mathrm{p}<0.001)$ and the manual condition $(\mathrm{p}<0.001)$. A post-hoc t-test confirmed that taskirrelevant interference was also higher in the ACC condition than in the manual condition $(\underline{\mathrm{t}}(109)=2.42, \underline{\mathrm{p}}<0.05)$.

An automation main effect was found for the task-related interference scale $(\underline{F}(2,202)=5.52$, $\mathrm{p}<0.01)$. Task-related interference was higher in the ACC condition $(\mathrm{p}<0.005)$ and the manual condition $(\mathrm{p}<0.05)$ than in the pre-driving condition.

An interaction effect between automation and traffic levels was found for task-related interference $(\underline{F}(4,202)=2.62, \underline{p}<0.05)$. In the medium traffic level, task-related interference was higher in the manual condition than in the pre-driving condition $(\mathrm{t}(37)=2.68, \mathrm{p}<0.05)$ and higher in the ACC condition than in the pre-driving condition $(\mathrm{t}(37)=3.07, \mathrm{p}<0.05)$. In the high traffic level, task-related interference was higher in the manual condition than in the pre-driving condition $(\underline{\mathrm{t}}(35)=2.41, \mathrm{p}<0.05)$ and higher in the ACC condition than in the pre-driving condition $(\underline{\mathrm{t}}(35)=2,79, \underline{\mathrm{p}}<0.05)$

An automation main effect was found for the tense arousal scale $(\underline{F}(2,202)=4.39, \underline{p}<0.05)$. Tense arousal was higher in the manual condition than in the pre-driving condition $(\mathrm{p}<0.005)$.

An interaction effect between automation and traffic levels was found for tense arousal $(\underline{F}(4,202)=4.28, \underline{p}<0.005)$. In the pre-driving condition, tense arousal was higher in the medium traffic level than in the low traffic level $(\mathrm{t}(72)=2.43, \mathrm{p}<0.05)$ and higher in the high traffic level than in the low traffic level $(\mathrm{t}(70)=2.03, \underline{\mathrm{p}}<0.05)$. In the medium traffic level, tense arousal was higher in the ACC condition than in the pre-driving condition $(\mathrm{t}(37)=2.20, \mathrm{p}<0.005)$. In the high traffic level condition, tense arousal was higher in the manual condition than in the pre-driving condition ( $\mathrm{t}(35)=3.62, \mathrm{p}<0.005)$ and higher in the ACC condition than in the pre-driving condition $(\mathrm{t}(35)=2.68, \underline{\mathrm{p}}<0.05)$.

\subsection{Summary of results}

The results of the ANOVA study are summarized in table 3 together with the implications for the experimental hypothesises.

INSERT TABLE 3 ABOUT HERE

\section{DISCUSSION AND CONCLUSIONS}


In summary, the ANOVA study shows six main findings. First, increases in traffic density are associated with slower speeds and traffic moving into the right-hand (overtaking) lane. Whilst these are obvious results, they do give some credibility for the accuracy of the simulation. Second, the locus of control scales were highly stable, which means that control loci were not affected by automation. Third, higher workload was experienced by participants in the manual condition, confirming that automation by invoking ACC was associated with reduced workload in normal operation. Fourth, workload is higher in higher traffic levels. Fifth, greater stress is associated with higher traffic also. These two points might lead us to suppose that ACC might be of greatest benefit at higher traffic levels. Finally, higher situation awareness was associated with the medium feedback condition (i.e., where information on the status of the ACC system was presented on the instrument cluster in the car).

The stability of locus of control is consistent with previous research. Previous research into manual driving has shown that 'externals' are less cautious, less attentive, and more likely to be involved in accidents than 'internals’ (Montag \& Comrey 1987, Holland 1993, Lajunen \& Summala 1995). This position might be exacerbated though automation. One possible solution to this problem might be to investigate driver training programmes that emphasize the development of an internal locus of control.

The reduction of workload in the ACC condition might be a cause for concern in very low traffic levels, whereas it could be a welcome relief under very high traffic levels. Workload research argues for an optimal level, neither underloading nor overloading the individual (Parasuraman \& Riley 1997). It is difficult to imagine how a seamless transition between manual and automatic headway control could be designed that would respond to changes in the level of road traffic. At present the decision to transfer control to ACC remains with the driver. Getting control back from ACC is fairly seamless, as it only requires the driver to brake or accelerate. As the ACC system has the potential to monitor the amount of braking and accelerating it and the driver are performing, it could prompt the driver to take control back under conditions of very low workload and suggest that ACC take over under conditions of high workload. Quite how this might be realized could be the subject of further research.

Increasing the driver's situation awareness is a key to successful automation. In this study it was found that provision of a head-up display (HUD) mirroring the ACC status from the instrument cluster display actually reduced reported situation awareness. Perhaps one of the reasons for this finding is that with the instrument cluster display, drivers could have discretion over when they wanted to sample the information, whereas with the HUD the data was displayed all the time. Therefore, the HUD might have made the driving task more visually complex (e.g., by adding clutter to the visual scene and even the process of blocking out the information requires some 
processing effort) and reduced overall situation awareness. Under low workload (i.e., low traffic conditions) the low feedback system (comprising the auditory warning only and no visual display) was found to lead to highest reported SA. Under these conditions the simplest interface is likely to be most appropriate, as it reduces driver distraction. Under medium and high traffic levels, associated with higher workloads, the medium feedback system (comprising the auditory warning and the LCD message display embedded in the instrument cluster) led to the highest level of reported SA. The irony here is, that the design considerations that optimize SA may well have a negative effect on workload and vice versa. For instance, if an interface is simplified to improve SA, this may also have the effect of reducing workload. Depending upon the context of performance, reductions in workload may not be desirable.

The ACC system certainly seems to fulfil its role as a comfort and convenience device, as it reduced both driver workload and anger when compared to manual driving. The stress reducing aspects of ACC are likely to be of most benefit at higher traffic levels, when driver stress is reported to be at its highest. This benefit does not, however, lead to increased 'understanding' of the situation in the ACC condition. One might expect that reducing the drivers' workload might plausibly be associated with increased SA as they have potentially greater opportunities to seek information and process it. This opportunity is counteracted by removal of the driver from the task of longitudinal control. In classic ergonomics research, this is referred to as out-of-the-loop control. There is no longer any requirement for the driver to attend to the feedback as s/he does not need it to control the vehicle. Bainbridge (1983) argued that the passive role of monitoring an automatic system is less satisfactory from a human performance perspective than the active role of controlling it. In this respect, Young \& Stanton (2005) draw a parallel between automation and skilled performance, or automaticity.

Driving, as a classic example of an automatic skill, is marked by unconscious processing of information and responding appropriately. Automation, too, removes the driver from conscious control of the driving task. If task demands change - perhaps due to some critical event on the road - both automaticity and automation require the driver to resume conscious control. However, Young \& Stanton (2005) argue that the driver using automation is at a disadvantage, due to the lack of a relevant knowledge base to draw upon in order to cope with the change in demands. The implication is that automation provides a kind of 'false expertise', whereby automation lulls drivers into a false sense of security.

This sense can extend to their metacognitive abilities, in particular their own perceptions of situation awareness. Experienced drivers, under manual control, are attending to numerous stimuli without really being aware of it. So whilst it might reasonably be argued that the driver 
has greater opportunity to sample the world when they are not involved in longitudinal control, they may not know what they should be attending to.

Ideally, we would like to design the ACC system so that it leads to the benefits of reduced workload and stress under high traffic density, but without reducing the driver's understanding. To understand how this might be achieved, we turn to the research on SA. There have been concerns for the reductions in pilot's SA with the advent of the glass cockpit (Jenson 1997). As with pilots, drivers need to track events in the world if they are to maintain adequate situation awareness. The situation awareness concept seems to be particularly appropriate for driving, as the driving task shares many of the same elements as the other domains in which SA has been used: multiple goals, multiple tasks, performance under time stress, and negative consequences associated with poor performance (Kaber \& Endsley 1997). In terms of Endsley's (1995) threelevel model, we would argue that the ACC interface should be designed in a manner that identifies features in the world to which the driver should attend to promote perception of the elements, comprehension of the current situation and projection of future status. Current design of ACC is largely centred on parsing messages about the status of the ACC system (e.g., messages on the mode ACC is in, such as: 'cruising', 'following', standby', or 'driver intervene'). The driver is required to integrate this information with what is happening outside the vehicle. Endsley (1995) argues that interface design should ideally provide an overview of the situation and support projection of future events, as well as providing cues of current mode awareness. To translate these guidelines into the design of ACC would require a radical departure from traditional in-car interface design. Typically, systems only report on their own status, they do not integrate these data with the status of other systems, nor do they offer any predictive information. This is not to say that it cannot be achieved however, as the ACC system readily processes much of this information already, it just does not display it to the driver yet.

Therefore the ACC system of the future may require a new kind of display, to help drivers identify cues in the world to which they should attend and offer predictions about their future trajectory in relation to their own vehicle. We imagine this information could be presented to identify potential conflicts between the driver's own vehicle and other vehicles based upon the trajectory of both vehicles. For example, the speed of the leading vehicle could be presented, and/or the difference in the two vehicles relative speed, and/or a recommended separation. Ideally, the design of the interface would need to reduce the reliance on drivers to make calculations and make comprehension and prediction easier (Endsley 1995).

To conclude, this study has shown that there are benefits associated with ACC as a comfort and convenience device. It should be pointed out that despite the morbid fascination with ACC in critical situations, in the study undertaken here, none of the drivers encountered life-threatening 
situations. ACC is likely to be of most use to the driver in high demand situations as a potential means of alleviating driver stress and workload. At present, the use of an HUD to present textual information on ACC mode status is not recommended, as it appeared to be associated with lower levels of reported SA. Future research should address this issue using objective measures of SA and designing interfaces that support SA acquisition with the minimum of cognitive effort.

\section{ACKNOWLEDGEMENTS}

The authors are gratefully acknowledge the support of the ESRC (grant reference L131251003) for their financial support of this project under the DETR Transportation and Operations Infrastructure Programme.

\section{REFERENCES}

BAINBRIDGE, L. (1983). The ironies of automation. Automatica, 19, 775-779.

BILLINGS, C. E. (1993). Aviation Automation: The Search For A Human-Centred Approach. (Mahwah, NJ: Erlbaum).

CARAMAZZA, A., McCLOSKEY, M., and GREEN, B. (1981). Naïve beliefs in "sophisticated" subjects: misconceptions about trajectories of objects. Cognition, 9, 117-123.

DE WAARD, D., VAN DER HULST, M., HOEDEMAEKER, M., and BROOKHUIS, K. A. (1999). Driver behavior in an emergency situation in the Automated Highway System. Transportation Human Factors, 1, 67-82.

DESMOND, P. A., HANCOCK, P. A., and MONETTE, J. L. (1998). Fatigue and automation-induced impairments in simulated driving performance. Transportation Research Record, 1628, 8-14.

ENDSLEY, M. R. (1995). Toward a theory of situation awareness in dynamic systems. Human Factors, 37, 32-64.

HANCOCK, P. A. (1997). Essays on the Future of Human-Machine Systems. (Minneapolis, MN: University of Minnesota).

HART, S. G. and STAVELAND, L. E. (1988). Development of NASA-TLX (Task Load Index): Results of empirical and theoretical research. In P. A. Handcock \& N. Meshkati (Eds.), Human Mental Workload (Amsterdam: Elsevier Science), 139-183.

HOEDEMAEKER, M. (1999, November 11). Cruise control reduces traffic jams. De Telegraaf.

HOEDEMAEKER, M, and BROOKHUIS, K. A. (1998). Behavioral adaptation to driving with an adaptive cruise control (ACC). Transportation Research Part F: Traffic Psychology \& Behaviour,_1, 95-106.

HOLLAND, C.A. (1993). Self-bias in older drivers' judgements of accident likelihood. Accident Analysis and Prevention, 25, 431-441. 
JENSEN, R. S. (1997) The boundaries of aviation psychology, human factors, aeronautical decision making, situation awareness, and crew resource management. International Journal of Aviation Psychology 7 259-267

JOHNSON-LAIRD, P. N. (1989). Mental models. In M. I. Posner (Ed.), Foundations of Cognitive Science. (Cambridge, MA. MIT Press), 469-499.

KABER, D. B., and ENDSLEY, M. R. (1997). Out-of-the-loop performance problems and the use of intermediate levels of automation for improved control system functioning and safety. Process Safety Progress, 16, 126-131.

LAJUNEN, T. and SUMMALA, H. (1995). Driving experience, personality, and skill and safety-motive dimensions in drivers' self-assessments. Personality and Individual Differences, 19, 307-318

MARSDEN, G., MCDONALD, M., and BRACKSTONE, M. (2001). Towards an understanding of adaptive cruise control. Transportation Research Part C: Emerging Technologies, 9, 33-51.

MATTHEWS, G., CAMPBELL, S., JOYNER, L., HUGGINS, J., FALCONER, S., and GILLILAND, K. (unpublished) The Dundee Stress State Questionnaire: an initial report. Dundee: Dundee University.

MATTHEWS, G., and DESMOND, P. A. (1995). Stress as a factor in the design of in-car driving enhancement systems. Le Travail Humain, 58, 109-129.

MATTHEWS, G., SPARKES, T. J., and BYGRAVE, H. M. (1996). Attentional overload, stress, and simulated driving performance. Human Performance, 9, 77-101.

MONTAG, I. and COMREY, A. L. (1987). Internality and externality as correlates of involvement in fatal driving accidents. Journal of Applied Psychology, 72 339-343.

MUIR, B.M. (1994). Trust in automation: Part 1. Theoretical issues in the study of trust and human intervention in automated systems. Ergonomics, 37, 1905-1922.

MUIR, B. M., and MORAY, N. (1996). Trust in automation. Part II. Experimental studies of trust and human intervention in a process control simulation. Ergonomics, 39, 429-460.

NILSSON, L. (1995) Safety effects of adaptive cruise control in critical traffic situations. Proceedings of the Second World Congress on Intelligent Transport Systems: "Steps Forward", Volume III (Tokyo: VERTIS), 1254-1259.

NORMAN, D, A. (1988) The Psychology of Everyday Things. (New York: Basis Books).

PAYNE, S. (1991). A descriptive study of mental models. Behaviour \& Information Technology, 10, 3-21.

PARASURAMAN, R. (2000). Application of Human Performance Data and Quantitative Models to the Design of Automation. Keynote address at the $3^{\text {rd }}$ International Conference on Engineering Psychology and Cognitive Ergonomics, Edinburgh, Scotland, October 25-27, 2000. 
also published in D. Harris (ed) Engineering Psychology and Cognitive Ergonomics Volume Five: Aerospace and Transportation Systems. Aldershot, Ashgate (3-13).

PARASURAMAN, R. and RILEY, V. (1997). Humans and automation: use, misuse, disuse, abuse. Human Factors, 39, 230-253.

PARKES, K. R. (1984). Locus of control, cognitive appraisal, and coping in stressful episodes. Journal of Personality and Social Psychology, 46, 655-668.

REINARTZ, S. J. and GRUPPE, T. R. (1993). Information Requirements to Support Operator-Automatic Cooperation. Human Factors in Nuclear Safety Conference. London, April 22-23.

RICHARDSON, M., BARBER, P., KING, P., HOARE, E., and COOPER, D. (1997). Longitudinal driver support systems. Proceedings of the I.Mech.E. conference, AUTOTECH '97 Paper number C524/064/97. (London, I.Mech.E), 87-97.

ROTTER, J.B. (1966). Generalized expectancies for internal versus external control of reinforcement. Psychological Monographs, 80, Whole no. 609.

SIMON, F. and CORBETT, C. (1996). Road traffic offending, stress, age and accident history among male and female drivers. Ergonomics, 39, 757-780.

SONMEZISIK, M., TANYOLAC, D., SEKER, S., TANYOLAC, A., HOEDEMAEKER, M. and BROOKHUIS, K.A. (1998). Behavioural adaptation to driving with an adaptive cruise control (ACC). Transportation Research Part F: Psychology and Behaviour, 1, 95-106.

STANTON, N. A. and YOUNG, M. S. (1998). Vehicle automation and driving performance. Ergonomics, 41, 1014-1028.

STANTON, N. A. and YOUNG, M. S. (2000). A proposed psychological model of driving automation. Theoretical Issues in Ergonomics Science, 1, 315-331.

STANTON, N. A., YOUNG, M. S., AND MCCAULDER, B. (1997). Drive-by-wire: the case of driver workload and reclaiming control with Adaptive Cruise Control. Safety Science, 27, 149159.

TAYLOR, R. M., SELCON, S. J. and SWINDEN, A. D. (1995). Measurement of situational awareness and performance. In R. Fuller, N. Johnston \& N. McDonald (Eds.), Human Factors in Aviation Operations. (Aldershot: Avebury).

WICKENS, C. D., GORDON, S. E. and LIU, Y. (1998) An Introduction to Human Factors Engineering. (New York, Longman).

WOODS, D.D. (1988). Coping with complexity: the psychology of human behaviour in complex systems. In L.P. Goodstein, H.B. Anderson, and S.E. Olson (Eds.), Tasks, errors and mental models: a festschrift to celebrate the $60^{\text {th }}$ birthday of Professor Jens Rasmussen (London: Taylor and Francis), 128-148. 
YOUNG, M. S. and STANTON, N. A. (1997). Automotive Automation: Investigating the impact on drivers' mental workload. International Journal of Cognitive Ergonomics, 1, 325336.

YOUNG, M. S. and STANTON, N. A. (2005). What's skill got to do with it? The role of automaticity in Malleable Attentional Resources Theory. Manuscript submitted for publication. 


\section{FIGURES AND TABLES}

Figure 1. Simplified state transitions for conventional cruise control.

Figure 2. Simplified state transitions for adaptive cruise control.

Figure 3. Driver tasks with CCC and ACC showing a mixture of cognitive and physical tasks (in the lozenge), cognitive tasks (in the oval) and physical tasks (in the rectangle).

Table 1. Numbers of participants assigned to experimental conditions.

Figure 4. Mean speed (mph) for the low, medium and high traffic conditions.

Figure 5. Mean lateral road position for the low, medium and high traffic conditions.

Figure 6. Frustration levels against feedback and automation.

Figure 7. Overall SA plotted against traffic levels and feedback.

Table 2. Statistics for mental models questionnaires according to experimental condition

Table 3. Summary of results 


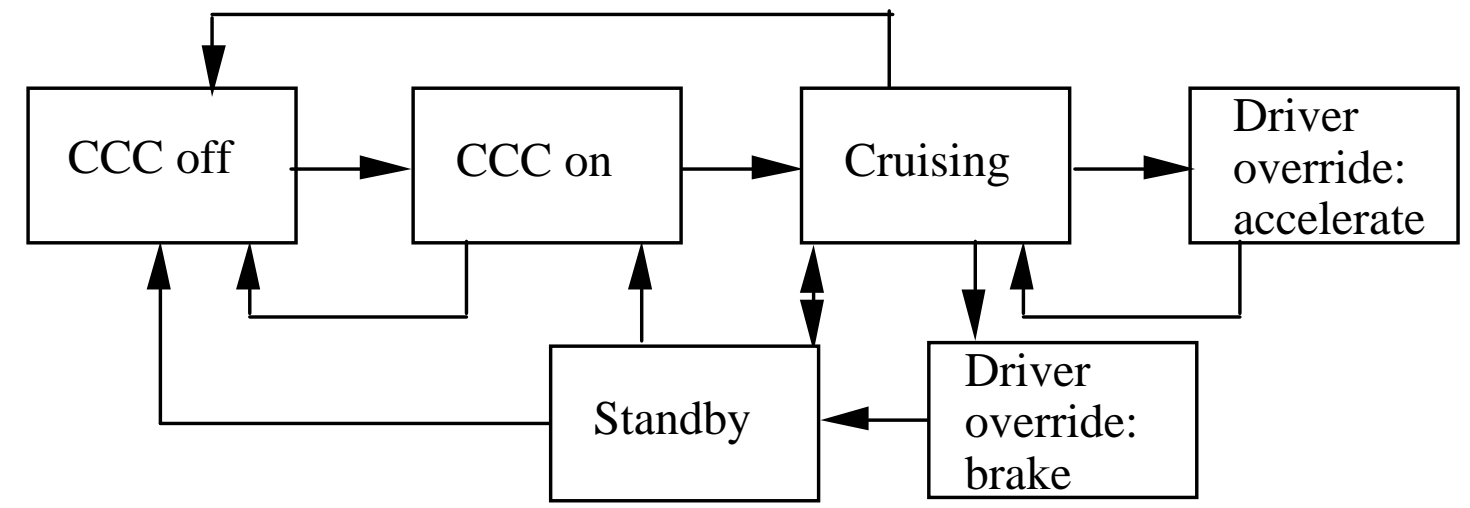

Figure 1. Simplified state transitions for conventional cruise control. 


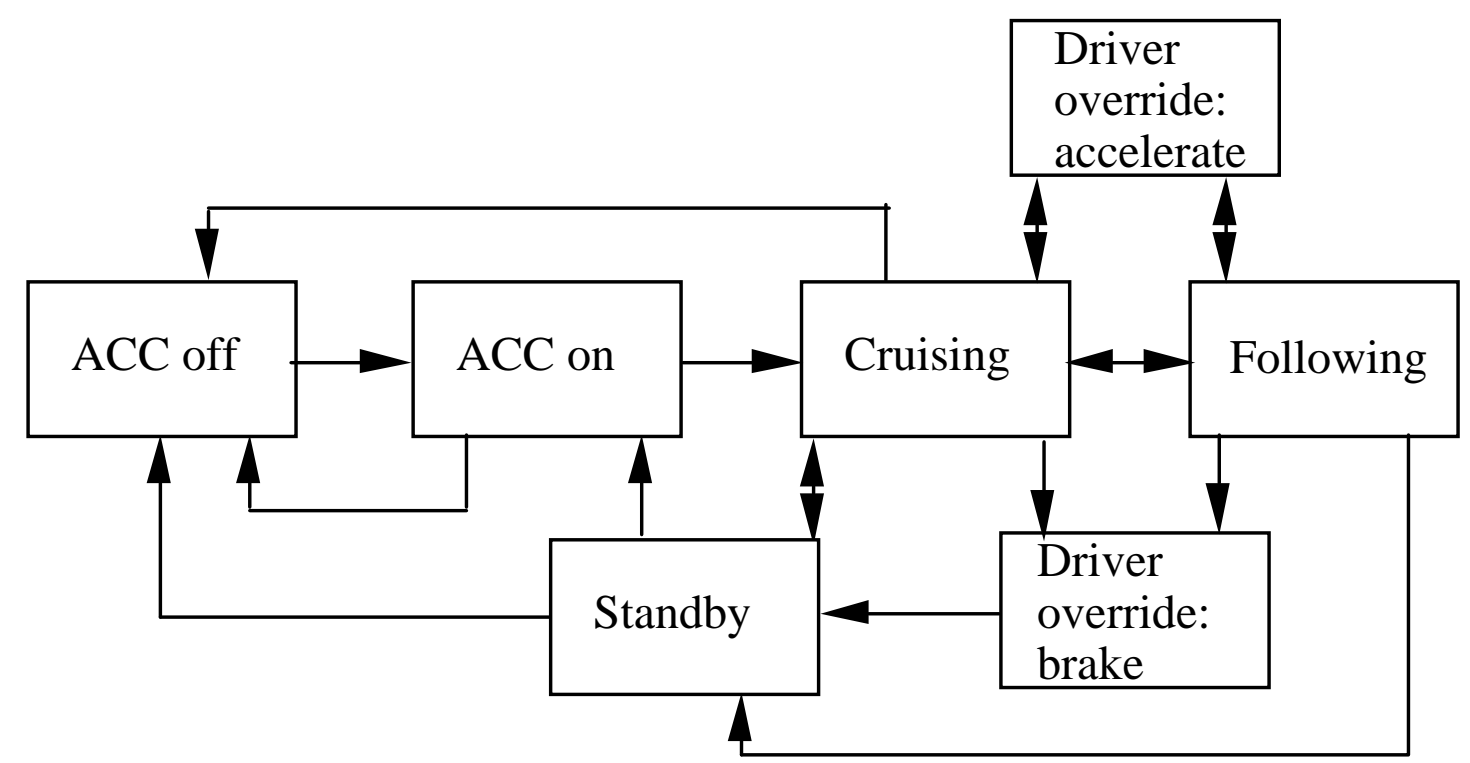

Figure 2. Simplified state transitions for adaptive cruise control. 


\section{DRIVER + CCC ACC SYSTEM IRIVER}

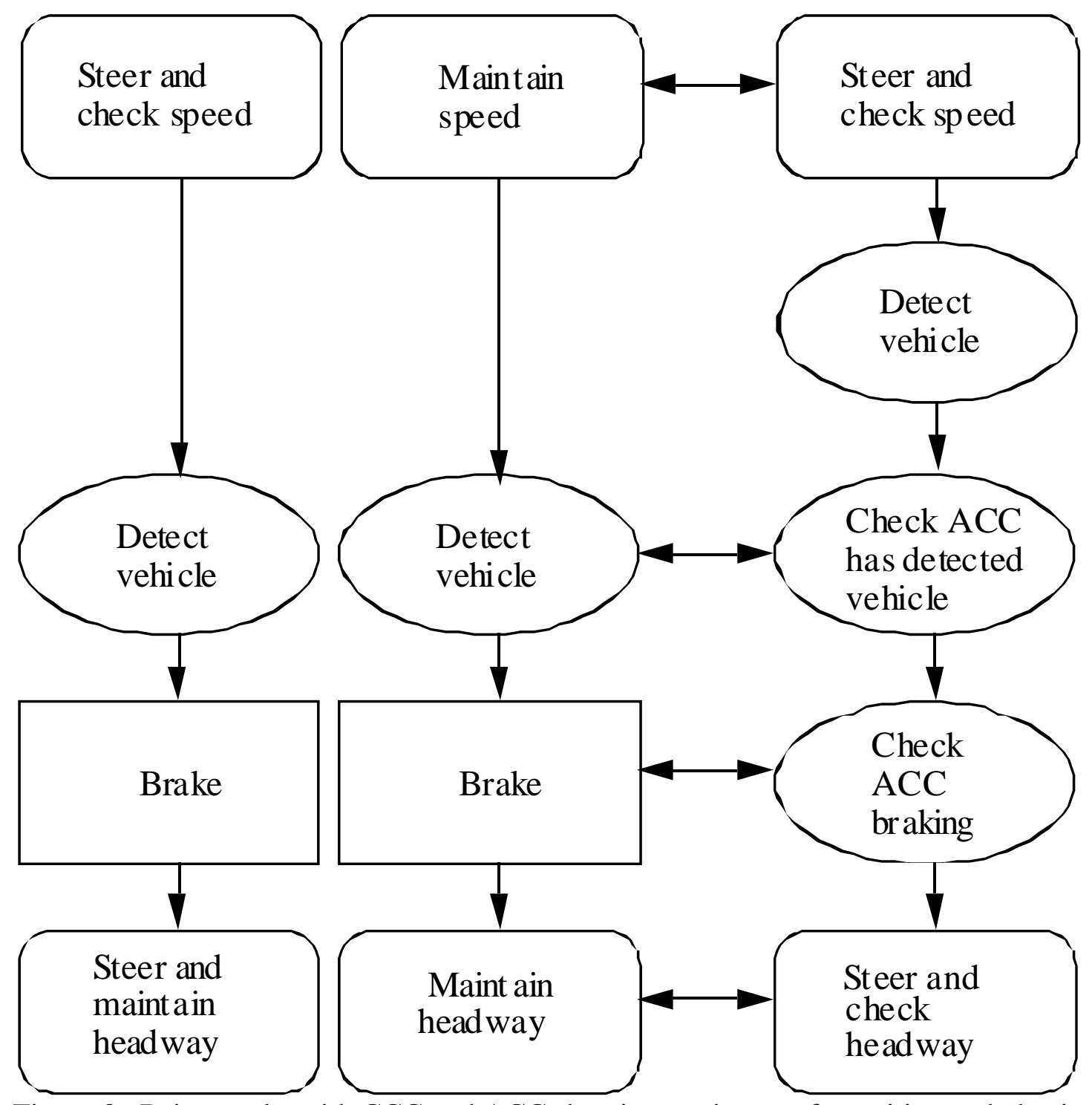

Figure 3. Driver tasks with CCC and ACC showing a mixture of cognitive and physical tasks (in the lozenge), cognitive tasks (in the oval) and physical tasks (in the rectangle). 


\begin{tabular}{|l|l|l|l|}
\hline Workload/Feedback & Low & Medium & High \\
\hline Low & 12 & 12 & 12 \\
\hline Medium & 12 & 14 & 12 \\
\hline High & 12 & 12 & 12 \\
\hline
\end{tabular}

Table 1. Numbers of participants assigned to experimental conditions. 


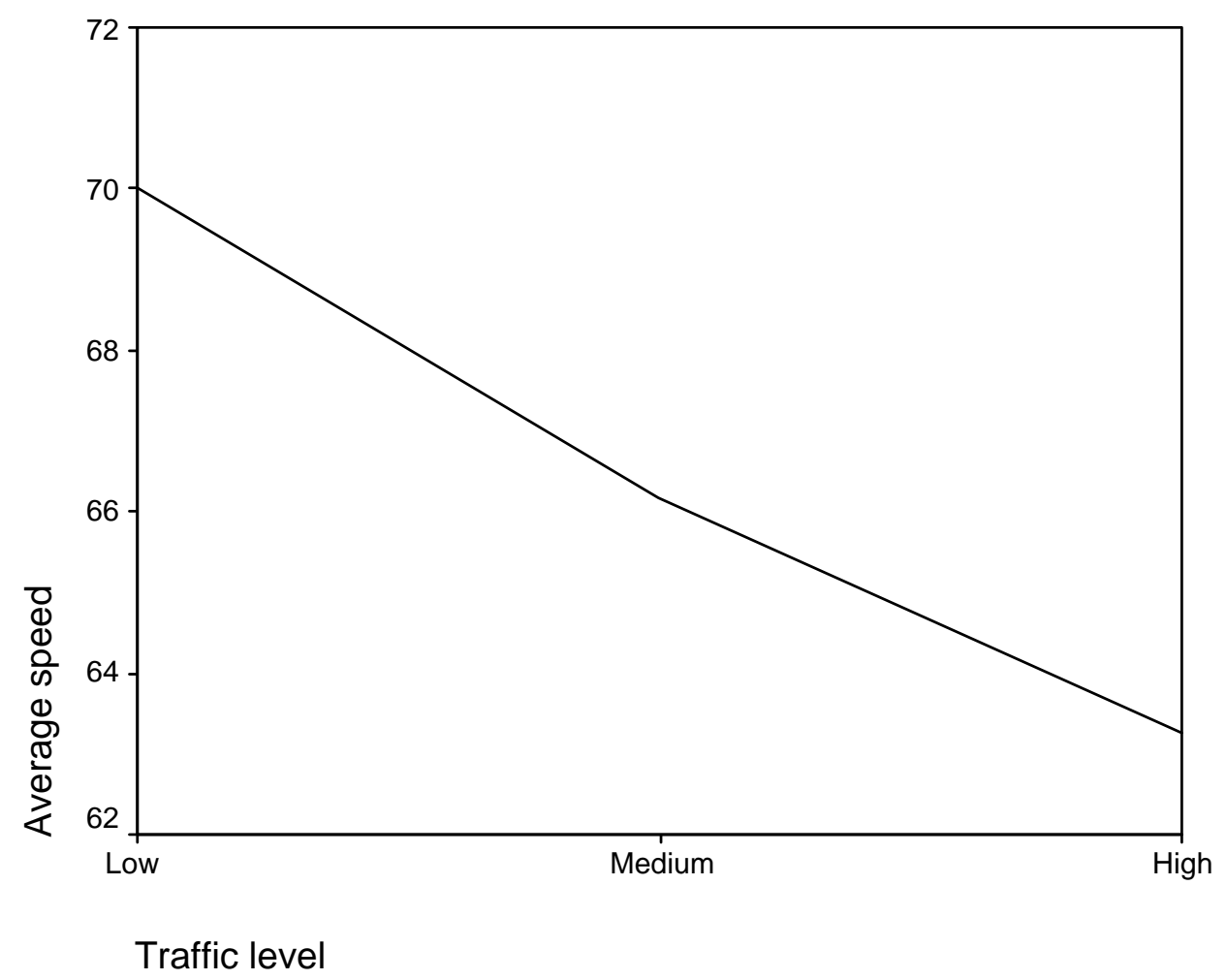

Figure 4. Mean speed (mph) for the low, medium and high traffic conditions. 


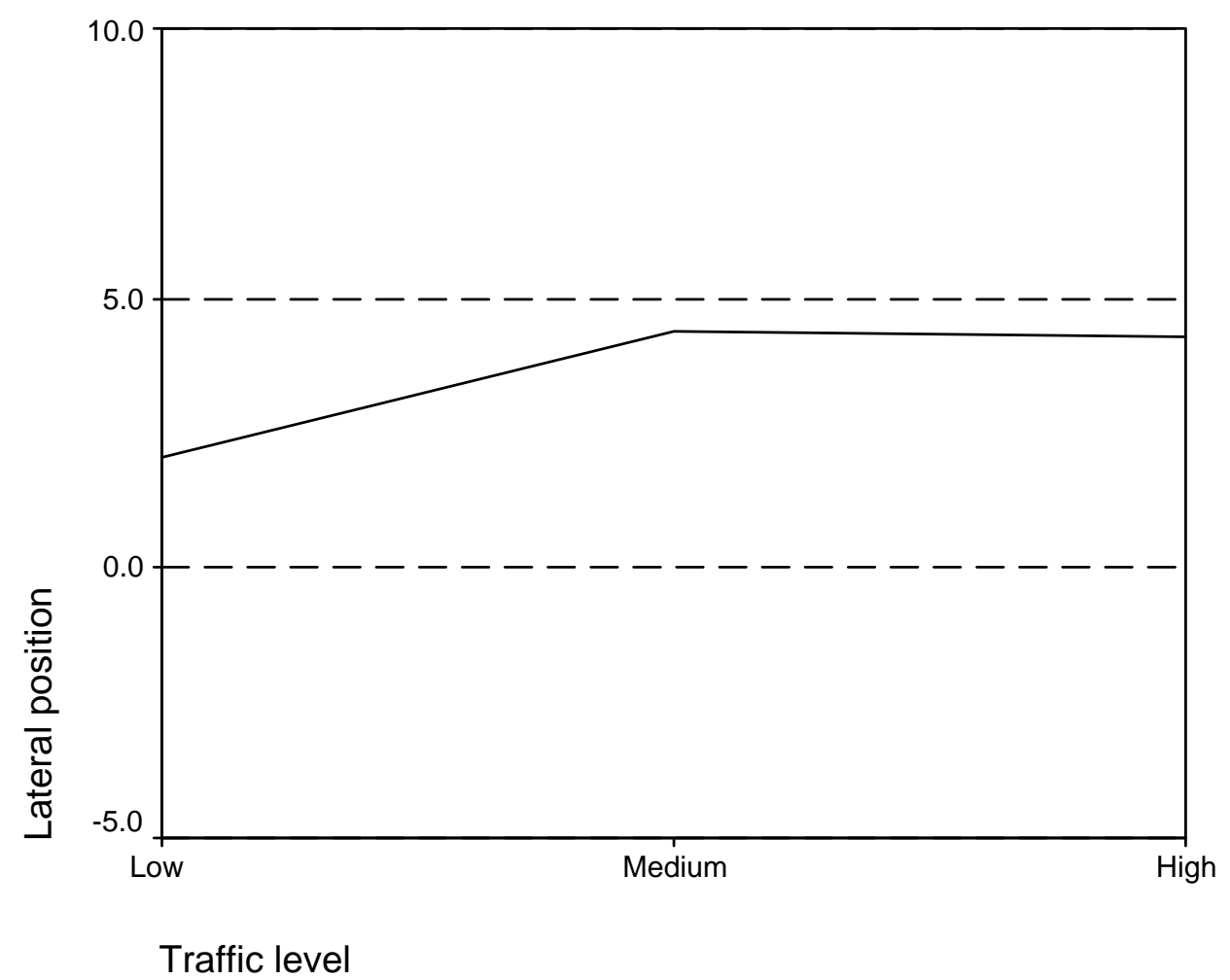

Figure 5. Mean lateral road position for the low, medium and high traffic conditions. 


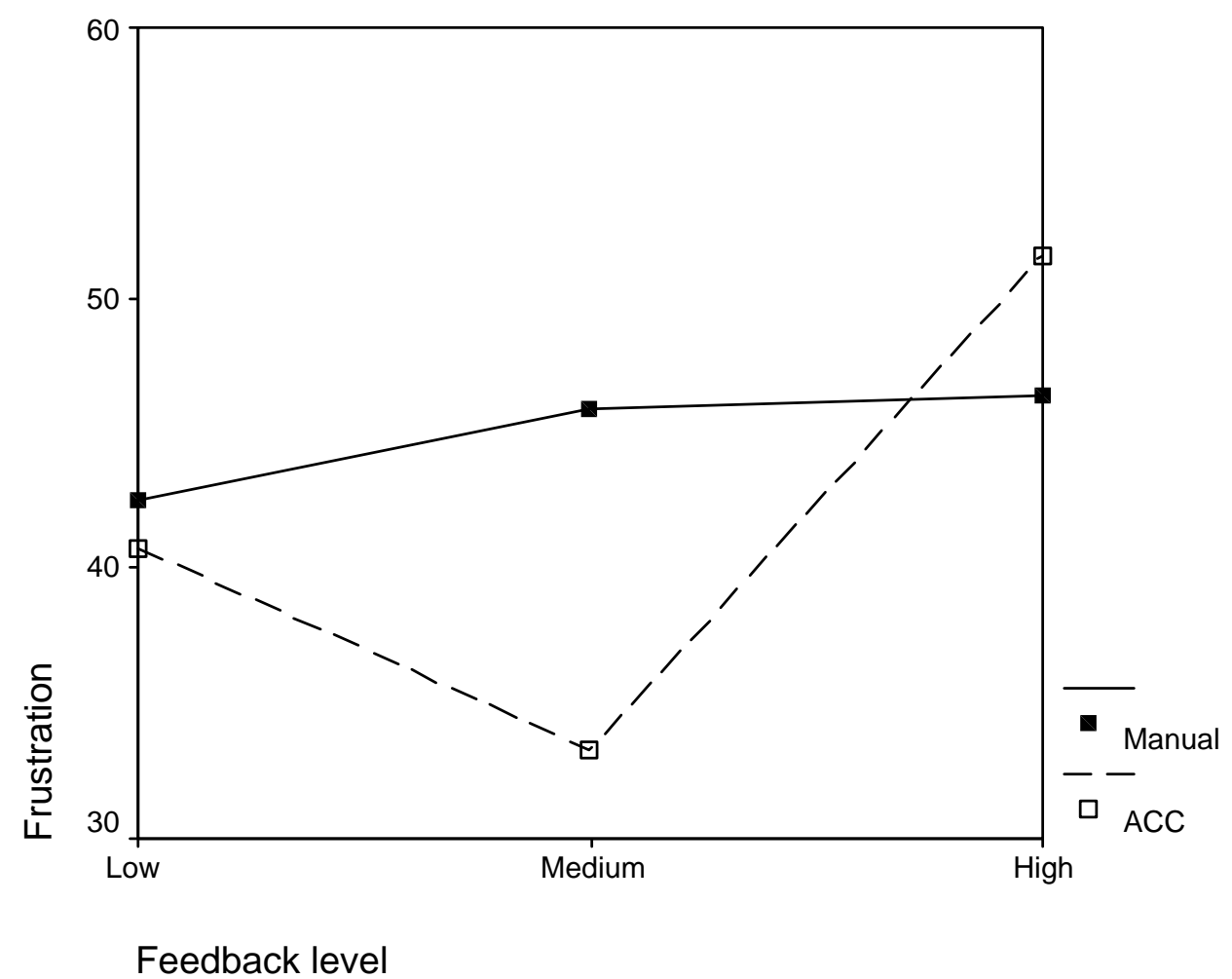

Figure 6. Frustration levels against feedback and automation. 


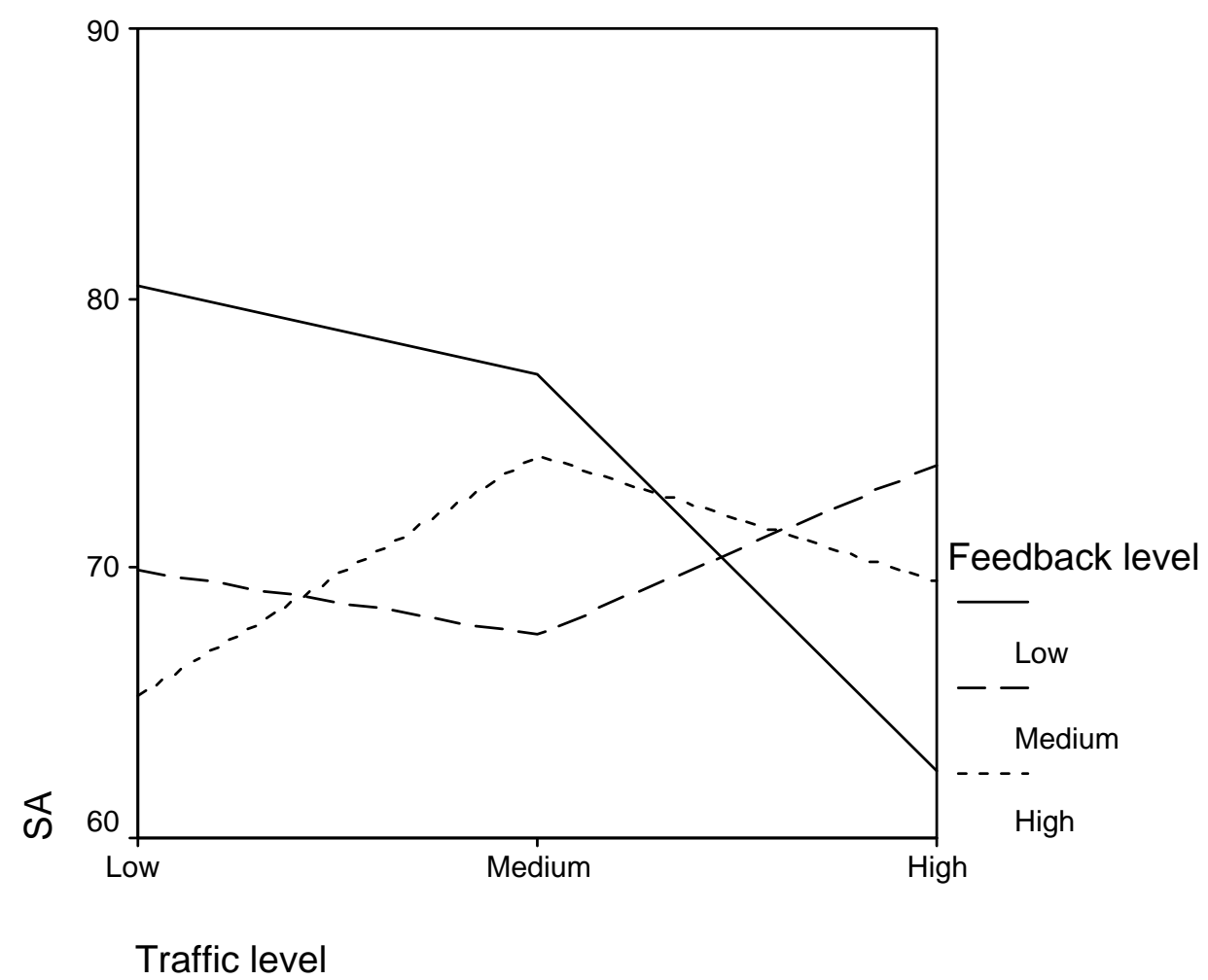

Figure 7. Overall SA plotted against traffic levels and feedback. 


\begin{tabular}{l|l|l|l} 
& Feedback & Traffic & Interaction \\
\hline Multiple-choice & $\underline{\mathrm{F}}(2,101)=1.22, \underline{\mathrm{p}}=\mathrm{ns}$ & $\underline{\mathrm{F}}(2,101)=0.55, \underline{\mathrm{p}}=\mathrm{ns}$ & $\underline{\mathrm{F}}(4,101)=1.03, \underline{\mathrm{p}}=\mathrm{ns}$ \\
\hline What happens next & $\underline{\mathrm{F}}(2,101)=1.65, \underline{\mathrm{p}}=\mathrm{ns}$ & $\underline{\mathrm{F}}(2,101)=1.13, \underline{\mathrm{p}}=\mathrm{ns}$ & $\underline{\mathrm{F}}(4,101)=0.49, \underline{\mathrm{p}}=\mathrm{ns}$ \\
\hline Verbal protocol & $\underline{\mathrm{F}}(2,101)=1.24, \underline{\mathrm{p}}=\mathrm{ns}$ & $\underline{\mathrm{F}}(2,101)=1.67, \underline{\mathrm{p}}=\mathrm{ns}$ & $\underline{\mathrm{F}}(4,101)=2.30, \underline{\mathrm{p}}=\mathrm{ns}$
\end{tabular}

$\underline{\text { Table 2. Statistics for mental models questionnaires according to experimental condition }}$ 


\begin{tabular}{|c|c|c|}
\hline Variable & Summary finding & Hypothesis \\
\hline Speed & Lower speeds with higher traffic levels & \\
\hline $\begin{array}{l}\text { Lateral } \\
\text { position }\end{array}$ & Medium and high traffic level more likely to be in the overtaking lane & \\
\hline $\begin{array}{l}\text { Locus of } \\
\text { control }\end{array}$ & $\begin{array}{l}\text { Medium traffic level condition has higher driving internality scores and lower } \\
\text { driving externality scores than the low or high conditions }\end{array}$ & H1=unsupported \\
\hline Trust & No statistical differences & $\mathrm{H} 2=$ unsupported \\
\hline $\begin{array}{l}\text { Situation } \\
\text { awareness (SA) }\end{array}$ & $\begin{array}{l}\text { For overall SA, under low traffic levels, low feedback leads to greater SA } \\
\text { than both high feedback and high traffic } \\
\text { Greater demand on attentional resources in manual driving compared to ACC } \\
\text { Greater supply of attentional resources in manual driving compared to ACC }\end{array}$ & H3=supported \\
\hline Mental models & No statistical differences & H4=unsupported \\
\hline Workload & $\begin{array}{l}\text { Greater overall workload in manual driving compared to ACC } \\
\text { Greater overall workload in medium and high traffic levels compared to low } \\
\text { traffic levels } \\
\text { Greater mental demand in manual driving compared to ACC } \\
\text { Greater mental demand in medium and high traffic levels compared to low } \\
\text { traffic levels } \\
\text { Greater physical demand in manual driving compared to ACC } \\
\text { Greater temporal demand in manual driving compared to ACC } \\
\text { Greater effort in manual driving compared to ACC } \\
\text { Greater frustration in medium and high traffic levels compared to low traffic } \\
\text { levels }\end{array}$ & H5=unsupported \\
\hline Stress & $\begin{array}{l}\text { Driving leads to greater stress than not driving } \\
\text { Driving in higher traffic levels leads to more stress than in lower traffic levels } \\
\text { Greater anger in manual driving than ACC } \\
\text { Greater task-irrelevant interference in ACC than manual driving }\end{array}$ & $\begin{array}{l}\text { H6=unsupported } \\
\text { H7=supported }\end{array}$ \\
\hline
\end{tabular}

$\underline{\text { Table 3. Summary of results }}$ 